\title{
PENINGKATAN PENDAPATAN MASYARAKAT DI MASA PANDEMI COVID-19 MELALUI PEMBERDAYAAN SUMBER DAYA ALAM KECAMATAN SERUWAY KABUPATEN ACEH TAMIANG
}

\author{
Meri Andriani $^{1}$, Hamdani ${ }^{2}$, Suri Purnama Febri ${ }^{3}$ \\ ${ }^{1}$ Prodi Teknik Industri, Teknik, Universitas Samudra \\ ${ }^{2}$ Prodi Teknik Mesin, Teknik, Universitas Samudra \\ ${ }^{3}$ Prodi Budidaya Perairan, Pertanian, Universitas Samudra \\ Email : (meri_tind@unsam.ac.id ${ }^{1}$ )
}

\begin{abstract}
Abstrak :
Kecamatan Seruway mempunyai daerah pesisir dengan pekerjaan Nelayan sebagai mata pencaharian utama penduduk. Permasalahan Mitra pada proses produksi dan pemasaran. Pada proses produksi, udang sabu sebagai material didapat tidak menentu, sementara sumber daya alam yang lain, Mitra tidak mempunyai pengetahuan cara memanfaatkannya. Alat manual pada proses produksi sehingga berlangsung lama, melelahkan dan terasi yang dihasilkan tidak bersih. Pada pemasaran, pengemasan sederhana dan tidak menarik, terasi dipasarkan hanya pada kawasan Kecamatan Seruway. Pemasaran terasi Mitra sangat merosot, apalagi dengan adanya pandemic Covid-19. disebabkan sedikitnya yang membeli terasi Mitra dan tidak pernah ada acara lagi yang diadakan oleh Pemerintah Daerah. Sementara untuk pemasaran online dan delivery, Mitra tidak tahu cara menggunakannya. Ketidaktahuan dalam menggunakan database untuk usaha, Mitra hanya mengandalkan perasaan dalam usahanya, tidak mengetahui cara mengelola keuangan dengan menggunakan aplikasi. Pandemi covid-19 ini tidak disiasati Mitra dengan memberdayakan sumber daya alam (darat) seperti kelapa. Virgin coconut oil (VCO) dan tempat bunga merupakan hasil dari kelapa sebagai solusi untuk Mitra. Solusi yang lain terhadap permasalahan Mitra adalah pemberian alat otomatis untuk meringankan pekerjaan dan mempercepat pekerjaan Mitra. Pelatihan dan pendampingan menggunakan alat yang diberikan, pelatihan pemasaran online dan delivery, pelatihan penggunaan database dengan menggunakan microsoft acces. Evaluasi dilakukan agar skill Mitra meningkat, terutama dalam teknologi dan penggunaan database. Mitra juga diberikan pelatihan cara membuat VCO dan pelatihan pembuatan tempat bunga dari serat kelapa. VCO dan tempat bunga dari serat kelapa merupakan alternatif untuk meningkatkan pendapatan dimasa pandemi covid-19 ini.

Kata Kunci : Antropometri, Ergonomi, Mitra, Pengabdian, Standard Nordiq Quesionnaire.
\end{abstract}

\section{Pendahuluan}

Kabupaten Aceh Tamiang merupakan salah satu Kabupaten yang berada di Propinsi Aceh. Kabupaten Aceh Tamiang mempunyai 12 Kecamatan yang termasuk didalamnya Kecamatan Seruway. Kecamatan Seruway dengan ibukota Peukan Seruway mempunyai luas daerah 188,49km2, dengan jarak tempuh ke Langsa sekitar 32,6 km dan waktu tempuh sekitar 48 menit. Penduduk Kecamatan Seruway mempunyai mata pencaharian sebagian besar adalah nelayan (Setyoko and Indriaty 2019) dan bertani. Selain menjual ikan, penduduk juga membuat terasi sebagai mata pencaharian. Terasi adalah bahan penyedap masakan yang padat (Nenabais et al. 2016) yang mempunyai bau khas, berasal dari bahan udang (Ulya and Ria 2016) atau ikan kecil yang diolah secara fermentasi (Permatasari, Sumardianto, and Rianingsih 2019) yang dilakukan secara tradisional (Romadhon, Rianingsih, and Anggo 2018) dan merupakan bumbu dari suku Aceh (Meri Andriani and Syntia 2020). Hasil Survey di lapangan, salah satu penduduk yang mempunyai mata pencaharian membuat terasi adalah Bapak Darwinsyah, beliau membuat Terasi dengan nama Belacan Tutok. Pak Darwinsyah membuat terasi dibantu oleh istri, dengan bekerja dari pagi sampai sore hari, alat yang dipergunakan dan proses penggilingan pada Gambar 1. 

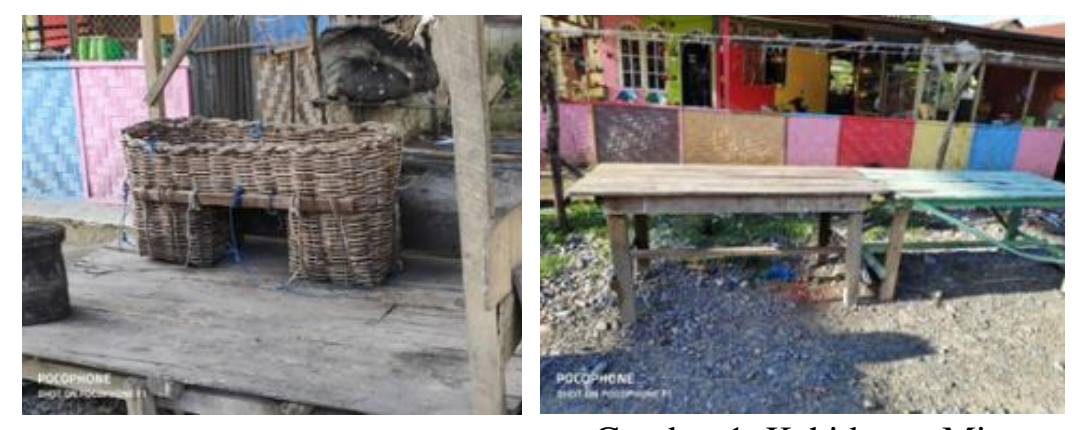

Gambar 1. Kehidupan Mitra

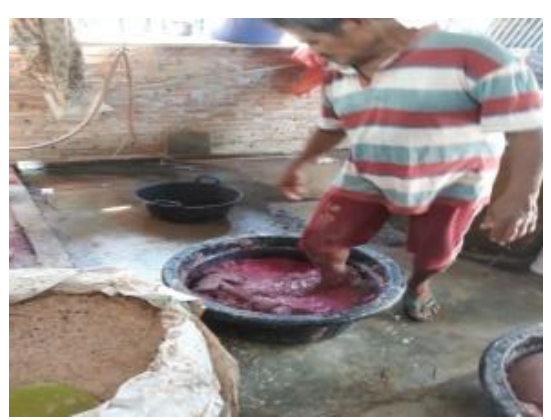

Gambar 1. alat yang dipergunakan dalam membuat terasi sangat sederhana dan manual dengan tempat yang kecil dan kurang bersih. Pada proses penggilingan dilakukan secara manual dengan cara, terasi yang sudah dicuci kemudian dipijak - pijak hingga halus. Proses sangat tidak bersih, tetapi Pak Darwinsyah tidak mampu membeli alat penggilingan.

Pada proses pencetakan terasi, Pak Darwinsyah melakukan dengan cara manual yakni satu alat cetak berukuran $15 \mathrm{~cm} \times 7 \mathrm{~cm} \times 3 \mathrm{~cm}$, dengan hasil cetakan 150 buah terasi/hari. Pak Darwinsyah mengeluhkan proses pencetakan membuat anggota badannya sangat lelah.

Pada proses pemasaran, terasi yang dipasarkan mempunyai kemasan yang sangat sederhana yakni plastik dan toples. Pak Darwinsyah mengatakan bahwa, beliau hanya tahu mengemas terasi dengan cara dibungkus plastik saja, sedangkan kemasan toples, beliau lakukan apabila ada toples kosong pemberian dari tetangga. Pemasaran terasi masih pada Kecamatan Seruway, dan juga apabila ada acara seperti acara bazar, ulang tahun Kabupaten Aceh Tamiang. Tetapi semenjak pandemi covid 19 ini, pemasaran terasi Mitra sangat merosot, disebabkan sedikitnya yang membeli terasi Mitra dan tidak pernah ada acara lagi yang diadakan oleh Pemerintah Daerah. Sementara untuk pemasaran online dan delivery, Mitra tidak tahu. Mitra juga mengalami ketidaktahuan dalam menggunakan database untuk usahanya. Mitra hanya mengandalkan perasaan dalam usahanya, tidak mengetahui cara mengelola keuangan dengan menggunakan aplikasi. Kemerosotan dalam pemasaran pada pandemi covid-19 ini tidak disiasati Mitra dengan memberdayakan sumber daya alam (darat) seperti kelapa. Kelapa banyak yang dapat dimanfaat, seperti minyak kepala yang dikenal dengan Virgin Coconut Oil (VCO) dan serat kelapa dapat dibuat tempat bunga. Mitra tidak tahu bagaimana cara memanfaatkan kelapa.

Permasalahan Mtra terdapat pada Tabel 1.

Tabel 1. Permasalahan Mitra

\begin{tabular}{|c|}
\hline \\
\hline
\end{tabular}




\section{Proses Penggilingan}

Proses pengilingan dilakukan agar terasi menjadi halus, tetapi penggilingan yang dilakukan secara manual. Penggilingan dilakukan dengan cara dipijak-pijak dengan menggunakan kaki, kaki yang digunakan juga tidak dicuci bersih terlebih dahulu.

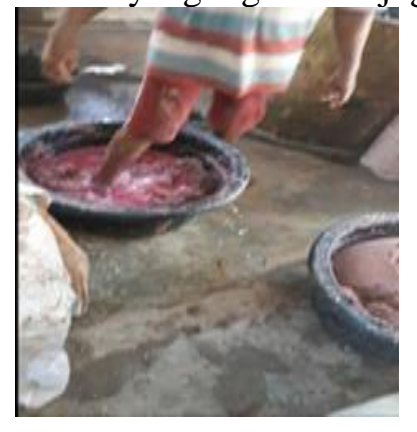

Proses Pencetakan Terasi

Proses pencetakan dilakukan secara manual, selain alatnya hanya satu, juga proses pencetakan ini perlu dilakukan pemadatan dengan cara ditekan kuat. Proses pencetakan ini memakan waktu yang lama dan juga banyak tenaga yang terkuras, sehingga Mitra mengalami kelelahan, dan produk terasi yang dihasilkan hanya 150 buah terasi dalam satu hari.

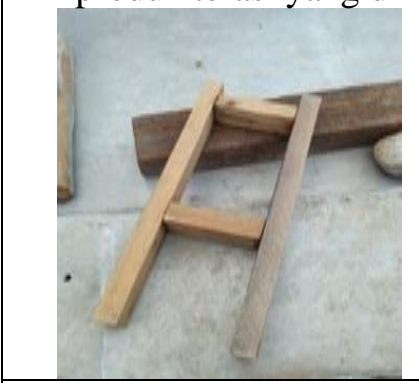

Proses Pemasaran

Proses pemasaran yang dilakukan Mitra hanya untuk kawasan Kecamatan Seruway saja.
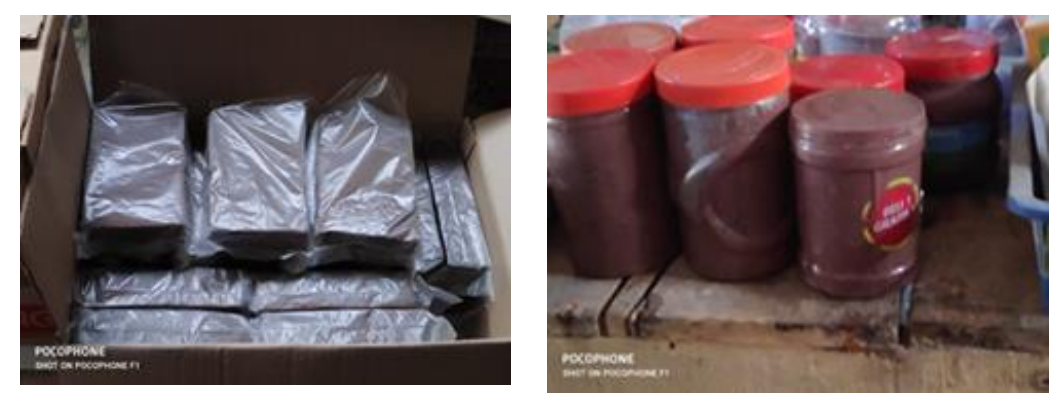

Selain itu kemasan terasi Mitra sangat tidak menarik sehingga perlu desain kemasan yang menarik. Mitra tidak mempunyai kemampuan untuk menjual terasinya keluar kota, apalagi pada saat pandemic covid 19 ini . 
Beberapa solusi permasalahan Tim Pengusul ajukan, terdapat pada Tabel 2.

Tabel 2. Solusi Permasalahan Mitra

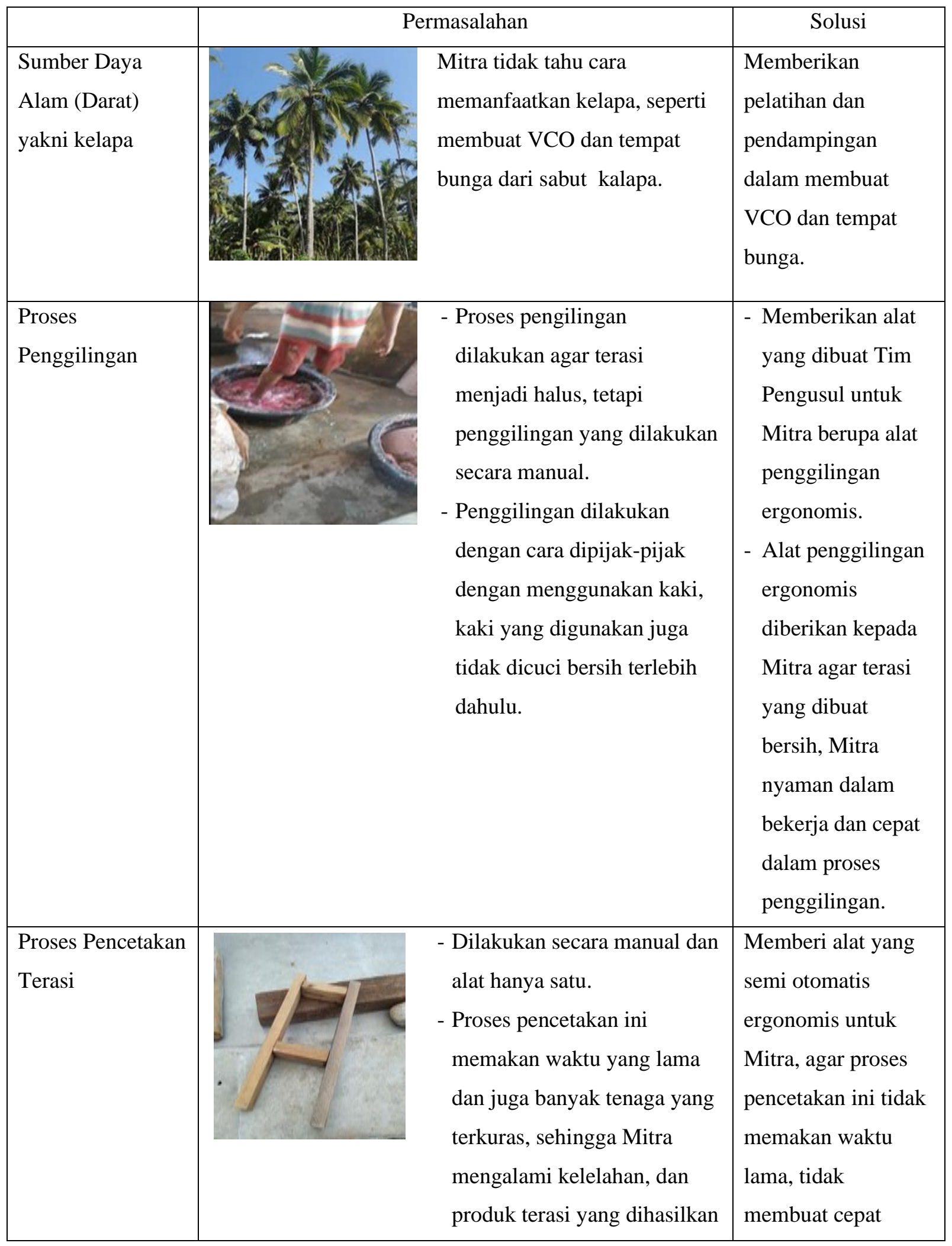




\begin{tabular}{|c|c|c|c|}
\hline & & $\begin{array}{l}\text { hanya } 150 \text { buah terasi dalam } \\
\text { satu hari. }\end{array}$ & $\begin{array}{l}\text { kelelahan dan lebih } \\
\text { banyak dapat } \\
\text { dicetak dalam satu } \\
\text { hari. }\end{array}$ \\
\hline Proses Pemasaran & rentin & $\begin{array}{l}\text { - Mitra hanya memasarkan } \\
\text { hanya untuk kawasan } \\
\text { Kecamatan Seruway saja. } \\
\text { - Kemasan terasi Mitra sangat } \\
\text { tidak menarik } \\
\text { - Mitra tidak mempunyai } \\
\text { kemampuan untuk menjual } \\
\text { terasinya keluar kota, apalagi } \\
\text { pada saat pandemic covid - } \\
19 \text { ini. }\end{array}$ & $\begin{array}{l}\text { Mendesain } \\
\text { kemasan menarik. } \\
\text { Memberikan alat } \\
\text { yang dapat } \\
\text { membantu dalam } \\
\text { memasarkan terasi } \\
\text { Mitra secara } \\
\text { online dan } \\
\text { delivery. } \\
\text { Mitra juga mampu } \\
\text { menggunakan } \\
\text { database. }\end{array}$ \\
\hline
\end{tabular}

\section{Metode}

Metode pelaksanaan dalam pengabdian yaitu :

1. Identifikasi kebutuhab Mitra,

Langkahnya : Tim pegabdi melakukan survey ke tempat Mitra dan melakukan wawancara

2. Perancangan sistem

Langkahnya : Tim pengusul melihat Mitra bekerja, kemudian merancang sistem baru dalam bekerja dengan menggunakan teknologi.

3. Pembuatan alat

Langkahnya : Alat dirancang kemudian dibuat alat dengan melihat kenyamanan Mitra dalam bekerja.

4. Pelatihan

Langkahnya : Pelatihan membuat VCO dan tempat bunga untuk meningkatkan pendapatan. Pelatihan penggunaan alat, pelatihan desain kemasan, pelatihan pemasaran dan pelatihan keuangan.

5. Pendampingan operasional

Langkahnya : Pendampingan dilakukan setelah dilakukan pelatihan. Seluruh pelatihan dilakukan pendampingan.

6. Implementasi Teknologi dan Evaluasi

Langkahnya : Tim pegabdi memberikan keterampilan membuat VCO dan tempat bunga dari sabut kelapa, memberikan alat, kemudian dilakukan pelatihan dan 


\section{(2) BAGIMU NEGERI : JURNAL PENGABDIAN MASYARAKAT \\ P-ISSN : 2548-8651 | E-ISSN : 2548-866X \\ Email : ejournal@umpri.ac.id}

pendampingan, Penggunaan microsoft acces dilakukan untuk mengelola bisnis Mitra, dilakukan evaluasi terhadap usaha Mitra, membuat market place agar pemasaran Mitra semakin luas.

Pada pengabdian dilihat keluhan dan juga membuat mesin yang dirancang secara ergonomi. Metode yang dipergunakan yaitu :

Ergonomi merupakan disiplin ilmu yang berkaitan dengan kemampuan dan keterbatasan manusia dalam menyelesaikan pekerjaannya (Meri Andriani and Anwar 2018).

Standard Nordiq Questionnaire (SNQ) atau Nordiq Body Map (NBM) merupakan identifikasi keluhan manusia pada tubuhnya. Perbedaan SNQ dengan NBM adalah pada tampilannya, untuk SNQ tampilannya berupa kuesioner dengan 28 atribut, sementara untuk NBM tampilannya berupa peta tubuh manusia dimana pada peta tersebut terdapat 28 titik keluhan.

Keusioner yang dipergunakan untuk SNQ berbentuk skala likert yakni penilaiannya mempunyai bobot, yaitu :

- Nilai 0, untuk keluhan tidak sakit,

- Nilai 1, untuk keluhan agak sakit,

- Nilai 2, untuk keluhan sakit,

- Nilai 3, untuk keluhan sangat sakit.

Antropometri merupakan ilmu yang berkaitan dengan pengukuran tubuh manusia yang dipergunakan untuk perancangan. Menurut (Sokhibi 2017), Antropometri dapat diaplikasikan pada perancangan area kerja (work station, interior mobil), perancangan peralatan kerja seperti mesin, equipment, perkakas (tools), perancangan produk konsumtif seperti pakaian, kursi/meja komputer, dan lain-lain, perancangan lingkungan kerja fisik.

\section{Hasil Dan Pembahasan}

Menjelaskan tentang hasil atau luaran pengabdian bisa berupa peningkatan pengetahuan, keterampilan atau berupa produk. Hasil juga mengemukakan tingkat ketercapaian target kegiatan. Jika berupa benda perlu ada penjelasan spresifikasi produk, keunggulan dan kelemahannya. Penulisan luaran perlu dilengkapi foto, tabel, grafik, bagan, gambar dsb. Pembahasan berurut sesuai dengan urutan dalam tujuan, dan sudah dijelaskan terlebih dahulu. Pembahasan disertai argumentasi yang logis dengan mengaitkan hasil PkM dengan teori, hasil PkM yang lain dan atau hasil penelitian. Kegiatan Pengabdian dilaksanakan dimulai dengan melakukan survey ke tempat Mitra. Hasil survey tersebut, Tim Pengabdian memberikan alat/mesin yang dibutuhlan Mitra agar Mitra dapat bekerja dengan nyaman sehingga dapat menghasilkan produk yang lebih banyak daripada sebelumnya, selain itu pelatihan dalam pembuatan VCO dan pot dari sabut kelapa juga merupakan solusi dari Tim Pengabdi sebagai alternatif usaha agar Mitra tetap mendapatkan pendapatan selain dari terasi. Alternatif ini dilakukan berhubung bahan terasi yakni udang kecepi sudah didapat, survey terdapat pada Gambar 2. 

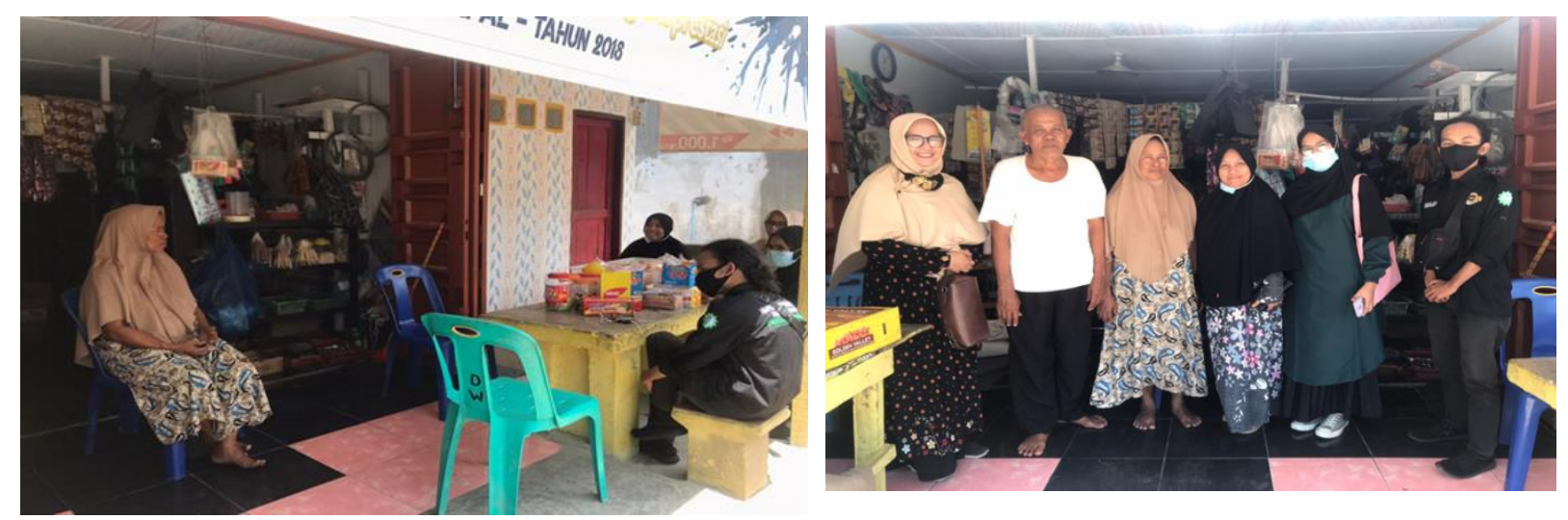

Gambar 2. Survey ke tempat Mitra

Kegiatan pengabdian diadakan pada tanggal 1 Agustus 2021 dengan kegiatan pemberian alat/mesin dari Tim Pengabdi kepada Mitra dan juga pelatihan VCO. Pemberian alat/mesin terdapat pada Gambar 3.
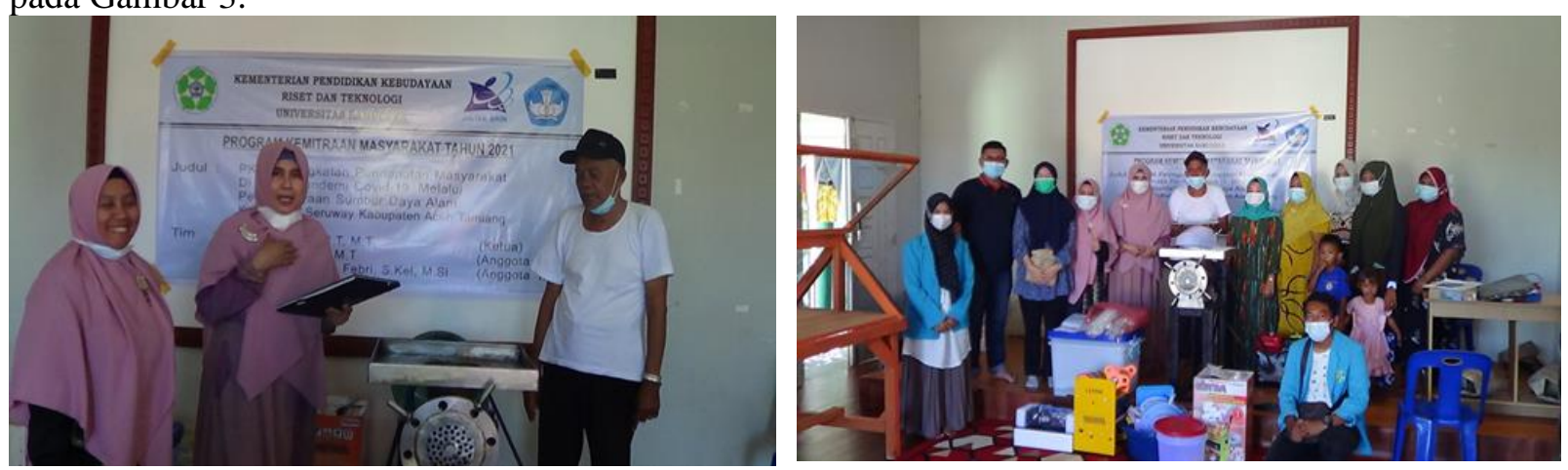

Gambar 3. Pemberian Alat/Mesin Kepada Mitra

Alat/mesin yang diberikan Tim Pengabdi bertujuan agar Mitra dapat bekerja dengan nyaman dan dapat menghasilkan produk yang lebih banyak. Salah satu mesin yang diberikan Tim Pengabdi yakni mesin penggiling terasi dirancang secara ergonomi agar Mitra dapat bekerja nyaman dan dapat meminimalkan kelelahan. Beberapa alat/mesin terdapat pada Gambar 4.
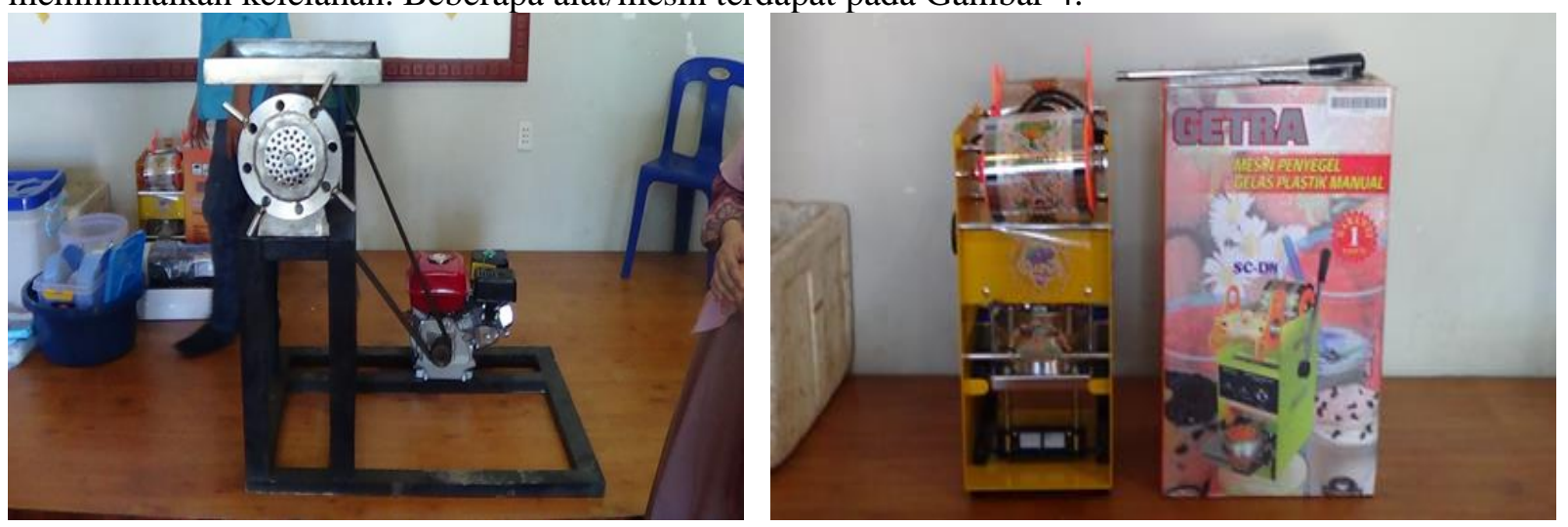

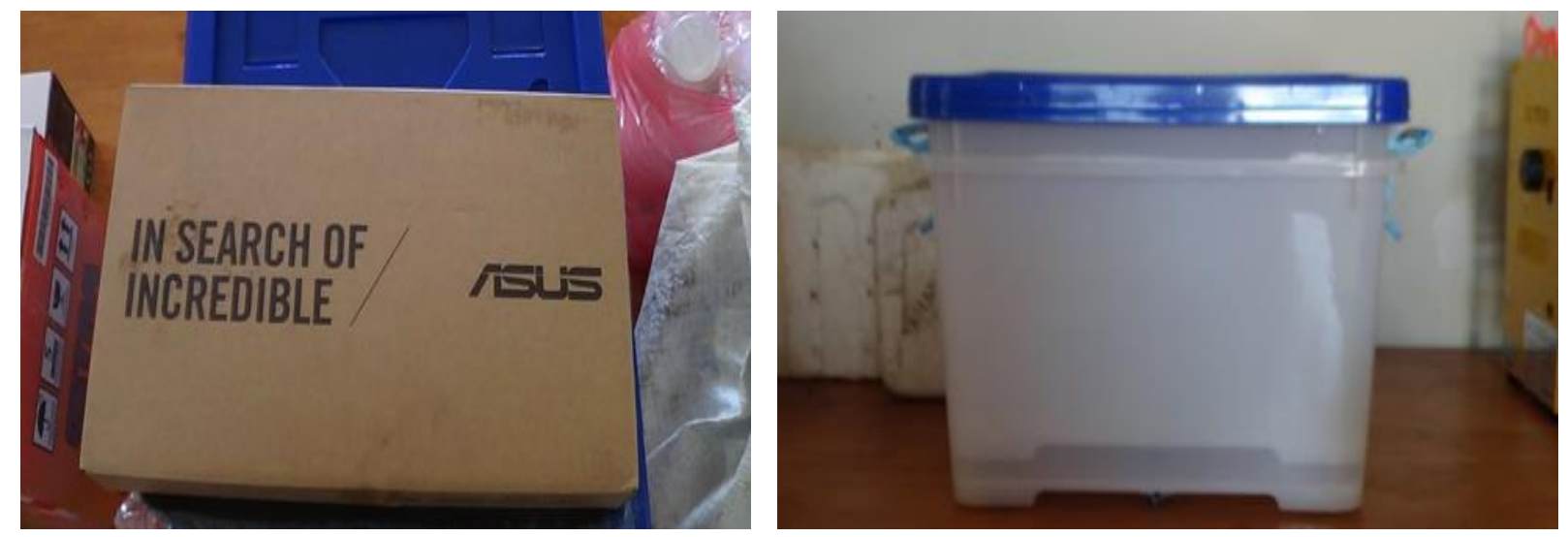

Gambar 4. Alat/Mesin Dari Tim Pengabdi

Pelatihan VCO dilakukan dengan pemateri memaparkan apa itu VCO dan manfaat serta keuntungan yang didapat. Pelatihan ini juga dilakukan dimulai dari mengukur kelapa kemudian dilakukan pemerasan santan, kegiatan ini dilakukan agar santan yang dihasilkan benar-benar kental sehingga dapat menghasilkan minyak VCO yang banyak. Pelatihan VCO ini terdapat pada Gambar 5.
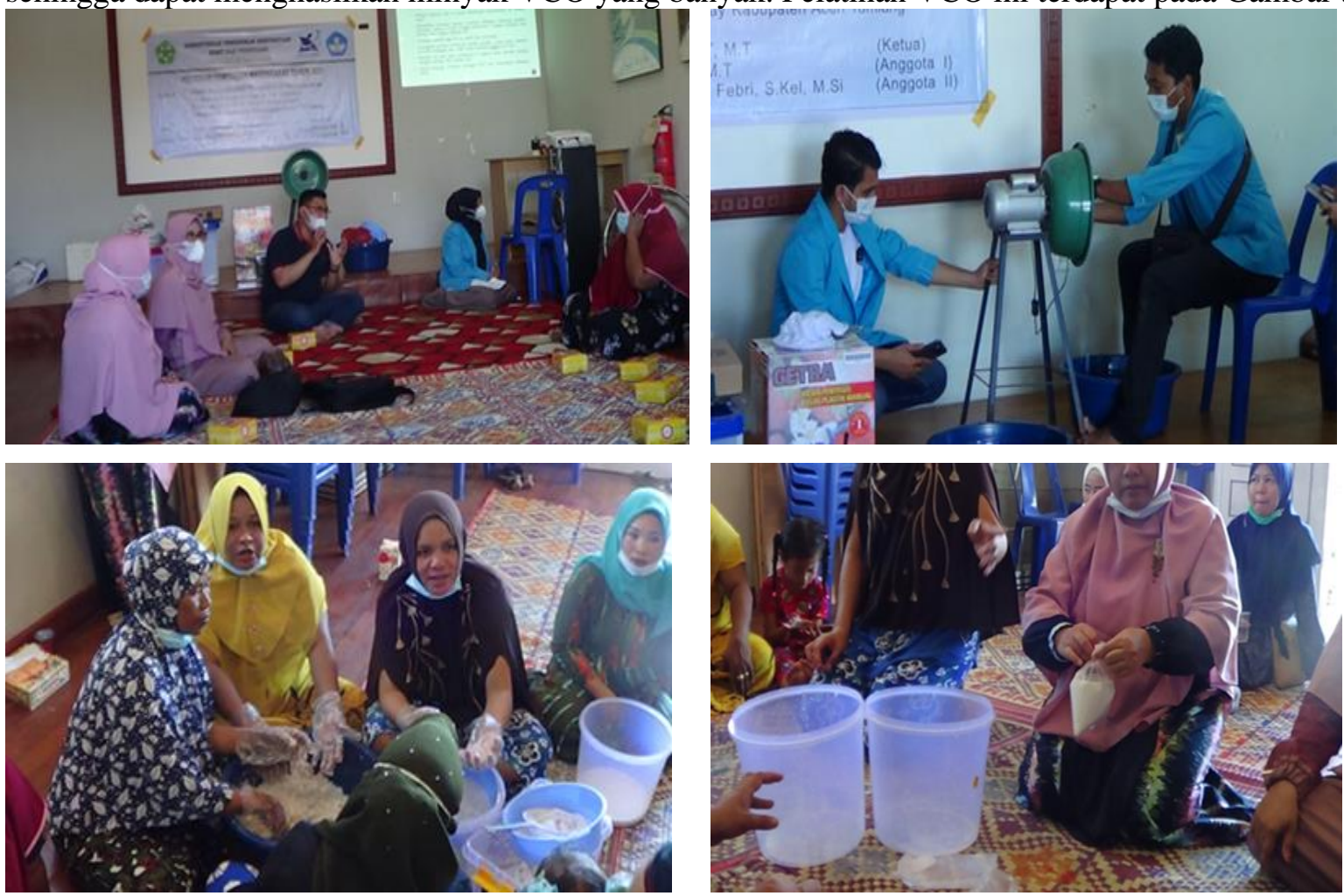

Gambar 5. Pelatihan Virgin Coconut Oil (VCO)

Pendampingan dilakukan oleh Tim Pengabdi pada tanggal 5 Agustus 2021 dengan tujuan mendampingi Mitra dalam membuat VCO tersebut. Hasil dari pelatihan pada tanggal 1 Agustus 2021, minyak VCO nya belum keluar sehingga Tim Pengandi menyarankan agar memindahkan olahan santan kental tadi kedalam cup agar Mitra dapat dengan mudah memindahkan minyak VCO tersebut apabila telah menjadi VCO, terdapat pada Gambar 6. 

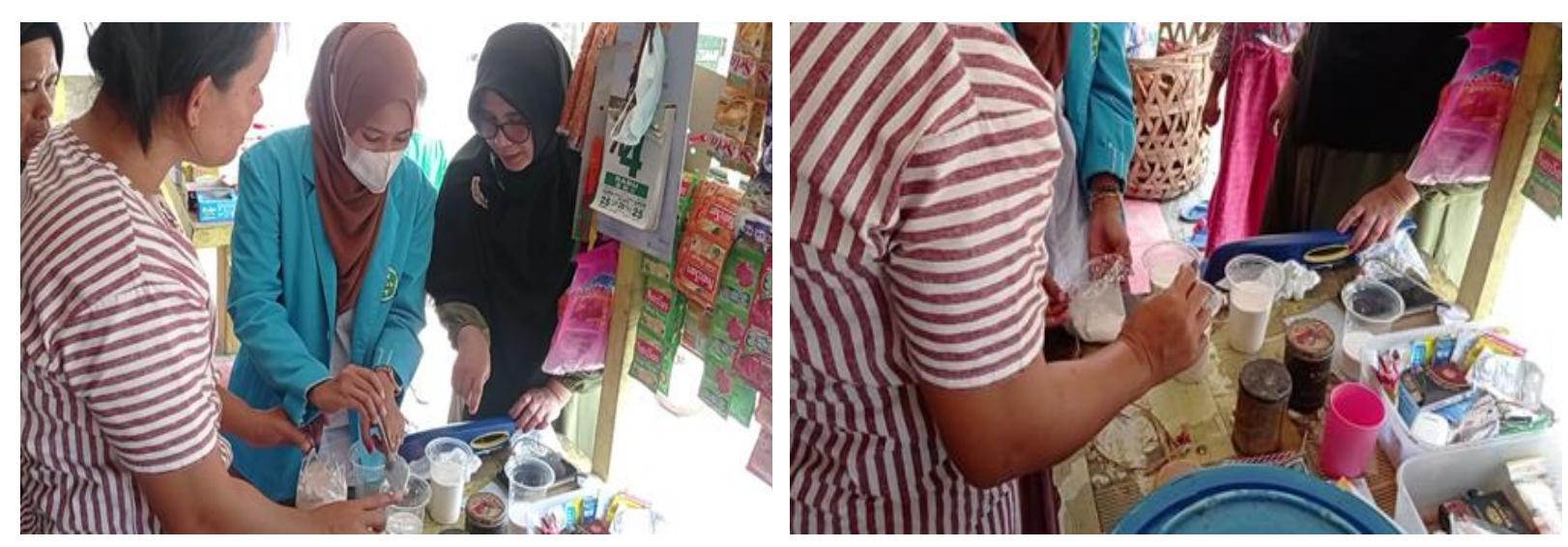

Gambar 6. Pendampingan Dalam Membuat VCO

Partipasi Mitra pada Program Kemitraan Masyarakat tahun 2021 ini adalah memberitahukan keluhan apa saja yang terdapat pada usahanya dan pada penggunaan alat yang manual yang dipergunakan oleh Mitra. Mitra memberitahukan keluhan bagian apa saja yang ada pada tubuh mereka selama Mitra menggunakan alat manual tersebut, begitu juga setelah menggunakan alat rancangan pengabdi. Keluhan yang diberitahukan oleh Mitra tersebut oleh Tim Pengabdi melakukan dengan memberikan kuesioner Standars Nordiq Quetionnaire (SNQ) yang harus diisi oleh Mitra. Kuesinoer SNQ dilakukan untuk melihat keluhan pada bagian tubuh manusia (Meri Andriani and Dewiyana 2015). Ada 28 titik keluhan yang tersebar pada tubuh manusia. Hasil dari kuesioner kemudian ditampilkan dalam Nordiq Body Map (NBM) terdapat pada Gambar 7.

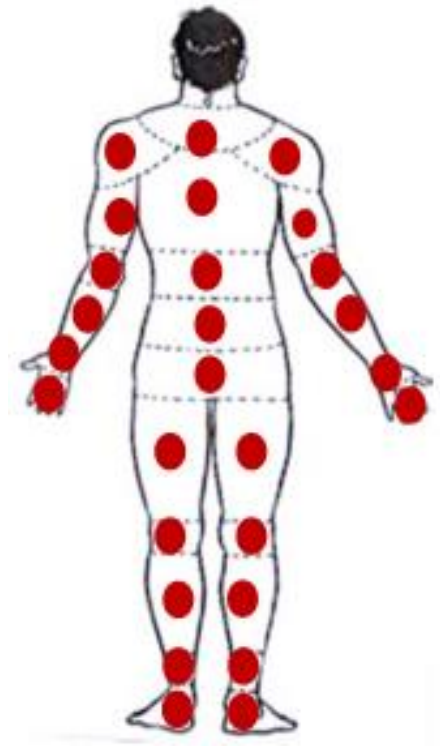

$\mathrm{a}$

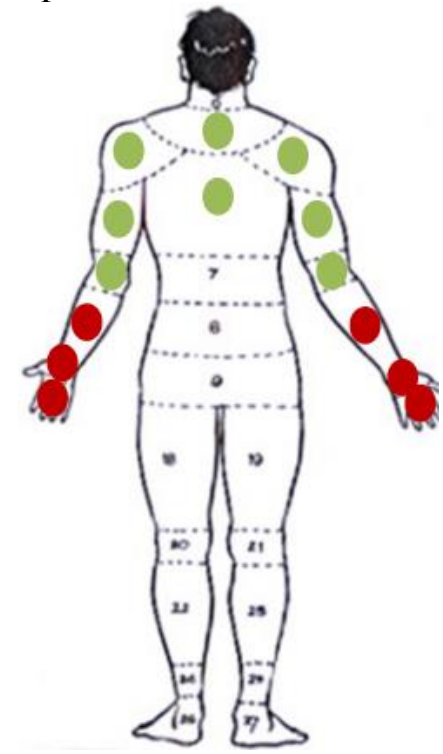

b

Gambar 7. Identifikasi Keluhan Mitra

Gambar 7 menunjukkan bahwa keluhan yang dirasakan Mitra sangat jauh berkurang. Pada bagian a, keluhan Mitra pada saat menggunakan alat manual, terlihat warna merah pada peta tubuh menandakan keluhan sakit, hampir seluruh titik keluhan, sementara pada bagian b, Mitra sudah menggunakan mesin yang dirancang oleh Tim Pengabdi secara ergonomi. Ergonomi merupakan disiplin ilmu yang berkaitan interaksi manusia dengan mesin atau alat (Hayati 2020) dan berkiatan dengan optimasi ditempat kerja (Wahyudin, Herwanto, and Nugraha 2020). Perancangan mesin secara ergonomi dimaksudkan bahwa ukuran mesin yang dirancang disesuaikan dengan ukuran tubuh Mitra. Perancangan mesin secara ergonomi dilakukan dengan menggunakan metode antropometri. Metode 


\section{(D) BAGIMU NEGERI : JURNAL PENGABDIAN MASYARAKAT \\ P-ISSN : 2548-8651 | E-ISSN : 2548-866X \\ Email : ejournal@umpri.ac.id}

antopometri merupakan ilmu dalam perancangan yang disesuaikan dengan ukuran (dimensi) tubuh manusia (M. Andriani 2019; Meri Andriani and Subhan 2016). Pada metode antropometri ada 70 dimensi manusia yang dipergunakan untuk merancang mesin. Dalam pengukuran antropometri ada beberapa faktor yang mempengaruhinya, diantaranya usia, usia anak-anak pasti berbeda ukuran tubuhnya dengan usia dewasa. Faktor jenis kelamin, ukuran tubuh pria berbeda dari ukuran tubuh wanita. Faktor suku bangsa, bangsa Asia berbeda ukuran tubuhnya dengan bangsa Eropah. Faktor pekerjaan, orang yang pekerjaannya kuli bangunan berbeda ukuran tubuhnya dengan ukuran tubuh manusia yang bekerja dikantor. Faktor cacat tubuh, manusia yang cacat tubuh berbeda ukuran tubuhnya dengan ukuran manusia normal. Faktor kehamilan, wanita yang hamil berbeda ukuran tubuhnya dengan ukuran wanita yang tidak hamil, atau ukuran hamil dua bulan berbeda dengan ukuran hamil Sembilan bulan.

Pada mesin secara ergonomi yang diberikan kepada Mitra ini adalah mesin penggiling terasi ergonomis. Mesin penggiling terasi ergonomis menggunakan satu dimensi yakni dimensi tinggi siku berdiri, terdapat pada Gambar 8.

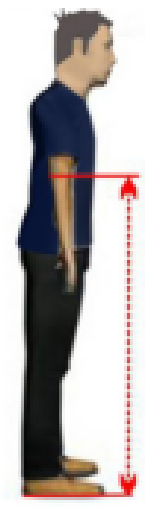

Gambar 8. Dimensi Tinggi Siku Berdiri

Gambar 8 menunjukkan cara pengukuran dimensi tinggi berdiri. Tujuan menggunakan dimensi tinggi siku berdiri adalah agar Mitra dalam menggiling terasi dapat bekerja secara efektif, nyaman, aman, sehat, efisien (ENASE).

Alat/mesin penggiling terasi dirancang dengan selain berpedoman kepada metode antropometri juga berpedoman pada metode persentil. Persentile adalah suatu nilai yang menunjukkan presentase tertentu dari orang-orang yang memiliki ukuran di bawah atau pada nilai tersebut (Tayyari \& Smith1997). Sebagai contoh, P5 percentile akan menunjukkan 95\% populasi akan berada pada atau di bawah nilai dari suatu data yang diambil.

Pembuatan alat/mesin penggiling terasi terdapat pada Gambar 9.

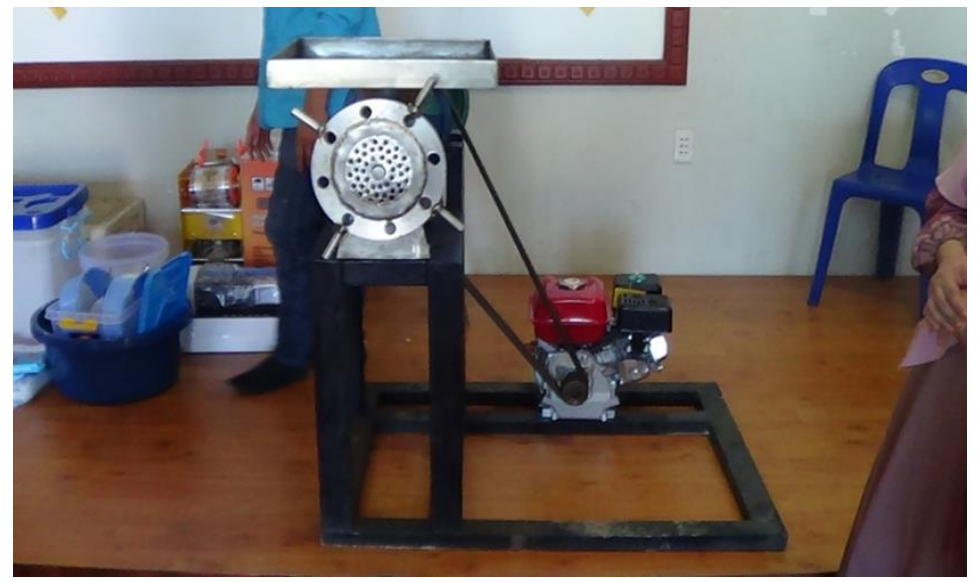

Gambar 9. Alat/Mesin Penggiling Terasi Ergonomis 
Gambar 9 menunjukkan mesin penggiling terasi yang ergonomis, agar Mitra dapat bekerja secara nyaman. Bekerja dikatakan ergonomi apabila Mitra bekerja dengan posisi berdiri tegak lurus.

Pengabdi juga memperhatikan pemasaran dari produk Mitra, maka pengabdi membuatkan market place untuk Mitra dengan tujuan pemasaran Mitra dapat terbar luas, buka hanya kawasan Kecamatan Tamiang saja. Market place yang dibuat adalah pada shopee, terdapat pada Gambar 10.

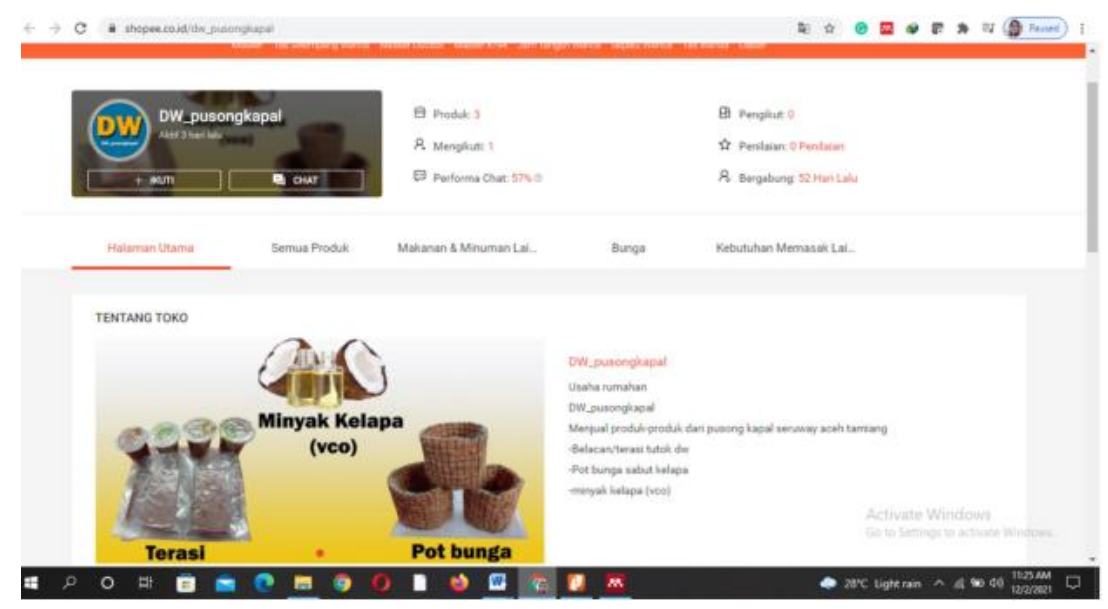

Gambar 10. Market Place di Shopee

Gambar 10 menunjukkan bahwa produk Mitra baik itu produk terasi maupun produk yang diusulkan oleh Pengabdi telah tampil dishopee dengan nama produknya DW pusong kapal.

Selain dibuat market place, Mitra juga dilatih untuk dapat menggunakannya, baik itu dilaptop maupun di handphone, terdapat pada Gambar 11.

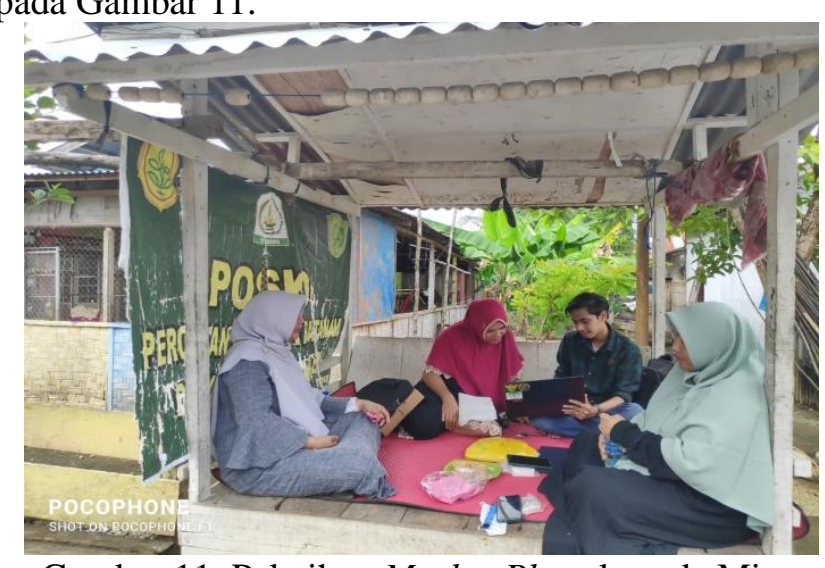

Gambar 11. Pelatihan Market Place kepada Mitra

Gambar 11 menunjukkan bahwa pelatihan dilakukan kepada Mitra dalam menggunakan laptop dan handphone untuk pemasarannya di market place.

\section{Simpulan Dan Saran}

Berdasarkan hasil pengabdian yang telah dilakukan maka dapat disimpulkan bahwa :

1. Pemberian alat/mesin yang diberikan benar-benar yang dibutuh oleh Mitra dalam usahanya.

2. Pelatihan yang diberikan berguna untuk menambah pendapatan Mitra dan juga alternative apabila usaha terasi tidak produktif yang disebabkan oleh bahan bakunya sudah didapat.

3. Pemasaran juga difokuskan oleh Tim Pengabdi untuk Mitra dengan memberikan pemasaran secara online dengan membuat market place (shope) agar usaha Mitra dapat berkembang apalagi pandemi Covid-19.

$\mathbf{7 5}$ | https://ejournal.umpri.ac.id/index.php/bagimunegeri 


\section{BAGIMU NEGERI : JURNAL PENGABDIAN MASYARAKAT \\ P-ISSN : 2548-8651 | E-ISSN : 2548-866X \\ Email : ejournal@umpri.ac.id}

Berdasarkan hasil pengabdian yang telah dilakukan maka saran yang diberikan adalah :

1. Alat/mesin yang diberikan oleh Tim Pengabdi dapat dipergunakan oleh Mitra dan dapat dijaga agar alat/mesin dapat bertahan lama.

2. Pelatihan yang diberikan kepada Mitra dapat dipergunakan pada usaha Mitra.

\section{Ucapan Terima Kasih}

Kami ucapkan terima kasih kepada Kementerian, Pendidikan, Kebudayaan, Riset dan Teknologi yang telah memberikan bantuan dana pada kegiatan pengabdian Kami.

\section{Daftar Rujukan}

Andriani, M. 2019. "Anthropometry Application of Students in the Design of Campus Tables and Chairs." Journal of Physics: Conference Series 1375(1).

Andriani, Meri, and Anwar. 2018. "Perbaikan Sikap Kerja Untuk Mengatasi Beban Kerja." Seminar Nasional IENACO 2018: 27-31.

Andriani, Meri, and Dewiyana. 2015. "Analisa Subyektifitas Dan Beban Kerja Secara Ergonomi Untuk Meningkatkan Produktivitas." 02: 6-10. www.unsam.ac.id.

Andriani, Meri, and Subhan. 2016. "Perancangan Peralatan Secara Ergonomi Untuk Meminimalkan Kelelahan Di Pabrik Kerupuk." Seminar Nasional Sains dan Teknologi 2016 Fakultas Teknik Universitas Muhammadiyah Jakarta (November): 1-10. jurnal.umj.ac.id/index.php/semnastek\%0Ap-ISSN.

Andriani, Meri, and Rita Syntia. 2020. "The Impact of Anthropometry on Terasi Packaging." IOP Conference Series: Materials Science and Engineering 854(1).

Hayati, ilma. 2020. "PENGUPASAN PISANG MENGGUNAKAN METODE ANTROPOMETRI DI IKM KERIPIK PISANG CIPAKU-CIAMIS.” 1(1): 147-52.

Maulana, Dina, Renty Anugerah, and Mahaji Puteri. 2019. "Usulan Perancangan Conveyor Untuk Mengurangi Keluhan Muskuloskeletal Pada Proses Packing Produk Dengan Aspek Ergonomi." JISI : Jurnal Integrasi Sistem Industri 6(1): 29-36.

Nenabais, Fernando, Feti Fatimah, Vanda S Kamu, and Ikan Cakalang. 2016. "Berdasarkan Hasil Uji Organoleptik The Optimization And Characterization Of Fish Paste Innards From Skip Jack, ( Katsuwonus Pelamis, L )." : 1-6.

Permatasari, Amelia Ayu, Sumardianto, and Laras Rianingsih. 2019. "Perbedaan Konsentrasi Pewarna Alami Kulit Buah Naga (Hylocereus Polyrhizus) Terhadap Warna Terasi Udang Rebon (Acetes Sp.)." Journal of Chemical Information and Modeling 53(9): 1689-99.

Romadhon, Romadhon, Laras Rianingsih, and Apri Dwi Anggo. 2018. "Aktivitas Antibakteri Dari Beberapa Tingkatan Mutu Terasi Udang Rebon.” Jurnal Pengolahan Hasil Perikanan Indonesia 21(1): 68.

Setyoko, Setyoko Setyoko, and Indriaty Indriaty Indriaty. 2019. "Etnozoologi Masyarakat Pesisir Seruway Aceh Tamiang Dalam Konservasi Tungtong Laut (Batagur Borneoensis)." Sainmatika: Jurnal Ilmiah Matematika dan Ilmu Pengetahuan Alam 16(1): 46.

Sokhibi, Akhmad. 2017. "Perancangan Kursi Ergonomis Untuk Memperbaiki Posisi Kerja Pada Proses Packaging Jenang Kudus." Rekayasa Sistem Industri 3(1): 61-72.

Ulya, S, and D S Ria. 2016. "Pemanfaatan Limbah Kepala Udang Windu ( Penaeus Monodon ) Untuk Pembuatan Terasi Dengan Kajian Penambahan Garam Dan Lama Fermentasi ( The Use of Penaeus Monodon Shrimp Head Waste for Terasi Product The Study of Salt Addition and Fermentation Time )." 10(1): 67-72.

Wahyudin, Wahyudin, Dene Herwanto, and Billy Nugraha. 2020. "Redesain Tata Letak Taman Bermain Outdoor Santri Raudhatul Atfal Dengan Metode Design Thinking Yang Ergonomis.” Performa: Media Ilmiah Teknik Industri 19(1): 69-76. 